\title{
EDITORIAL
}

\section{Voicing the natural way}

\section{Sanjay N Jain}

Editor-in-Chief, The Indian Journal of Radiology and Imaging, Prince Aly Khan Hospital, Aga Hall, Nesbit Road, Mazagaon, Mumbai - 400 010, Maharashtra, India. E-mail: editor@ijri.org

Nature is the supreme visible power in front of us, and all of us are her innumerable integral components. Size is immaterial as regards the contribution to upkeep her balance, all that counts is that each and every minute constituent has a powerful role to play, which leads us to sanely conclude that one element is not, in any way, superior or inferior to another; hence, we all coexist. Man, who stands on the top of this balance, is expected to observe and guide it, perhaps has taken the role of governing this parity. When significance of equilibrium between the head and the heart goes for a toss, the fall out is the fury of mother nature, in mammoth proportions, if the calamities at the ancient religious sites in Uttarakhand are any indications in this regard. ${ }^{[1]}$ While the state is still limping to recovery, what environmental scientists feel is that the areas which have been affected would take close to 20 years to convalesce. Hence, the indelible understanding of the fundamental rules of never to disrespect or tamper with the laws of nature. Respect and get respected.

The initial few months have witnessed a myriad of differing feedbacks from a few quarters. A school of thought has emerged stressing the need for more case reports' inclusion. Possibly if we look back, while many of us would have begun our career with a case report, the current times are not in keeping with the same. The most important perspective perhaps here is that there is not much learning from them. Also, many of the reviewers today by and large almost instantaneously decline to review them ${ }^{[2]}$ In addition, we find many of these articles to be poorly structured. On the other hand, case series would have better acceptance rate with a better overall review of the topic in question. Overall with overseas submission from authors of nonEnglish speaking countries, it is very difficult to make them understand our requirement as the article progresses, especially at the time of revision up to completion. I guess they need to take the help of a native English professor to

\begin{tabular}{|l|l|}
\hline \multicolumn{2}{|c|}{ Access this article online } \\
\hline Quick Response Code: & \\
\hline & Website: \\
\hline & www.ijri.org \\
\cline { 2 - 3 } & DOI: \\
\hline
\end{tabular}

comprehend our requirement and then go ahead. A steady flow is needed in every article as it enhances its strength.

The Computers and Related Technology section begins with one of the most innovative technologies to enter the imaging reporting cabin; namely voice recognition. ${ }^{[3]}$ The various pros and cons apart, it does promise to make reporting faster and accurate provided template-based reporting is adopted. One of the distinct challenges while operating this technology is to attend to a telephone call, a charging emergency physician etc.; it is just difficult if not impossible to do anything else. Complete focus is needed as words may be wrongly spelt along with possible few jumps to other sentences.

Commonly used alkylating agents such as monohalomethanes could be responsible for toxic encephalopathy, as highlighted in one of the articles. One of the uncommon causes of delayed progressive neurological deficit includes herniation of spinal cord into nerve root avulsion pseudomeningocele, as illustrated in the featured neuroradiology section, amongst others.

The Head and Neck section deals with a couple of articles dealing with various aspects of pseudoaneurysm formation in internal carotid artery and rhinosporidiosis. The latter is endemic in few areas within India and various imaging features are dealt with emphasis on surgical road map planning.

Dense breasts continue to be an enigma in contemporary imaging. The emergent role of contrast-enhanced digital mammography in such situations is highlighted in one of the technical note section articles.

Abdominal Radiology/Genitourinary and Obstetrics section section deals with an interesting sum of variations of celiac axis, common hepatic artery CT anatomy, need of the hour as a lot of work is done contemporarily in interventional radiology, transplants patients. A comprehensive pictorial essay on the role of magnetic resonance imaging (MRI) in staging carcinoma of cervix is depicted with emphasis on current treatment strategies. In addition, various articles on treatment planning in transrectal ultrasonography (USG)-guided aspiration of prostatic abscess, unusual complications of cesarean scar, 
fetal endocardial echogenicity in organophosphate (OP) poisoning, and validation of the global reference for fetal weight and birth weight percentiles in the Indian scenario.

Ultrasonography section highlights the current role of highresolution USG in the diagnosis of various cutaneous lesions with an article on Musculoskeletal (MSK) application.

The last featured article is a technical note on Thermography and its current applications in ocular diseases.

While we march ahead in pursuit of keeping the professional torch burning against the blowing winds, by equipping ourselves with the latest available information, let's also work towards the goal of applying ourselves towards professional excellence; thereby, upkeeping trust, not only during normalcy, but also during troubled times as well.
Before I take leave, very soon you would be hearing from me on theme-based issues of IJRI, as in the case of few leading international radiology journals (RadioGraphics, BJR, Radiology). Please keep pouring with your inputs on any aspect of Radiology which you wish to draw attention to, so that, we march ahead at the same wave length.

\section{References}

1. Available at http://en.wikipedia.org/wiki/2013_North_India_ floods.

2. Buckley O, Torreggiani WC. The Demise of the Case Report. AJR Am J Roentgenol 2007;189:W54-5. Available at http://www. ajronline.org/doi/pdf/10.2214/AJR.07.2203.

3. Krishnaraj A, Lee JK, Laws SA, Crawford TJ.Voice recognition software: effect on radiology report turnaround time at an academic medical center. AJR Am J Roentgenol 2010;195:194-197 